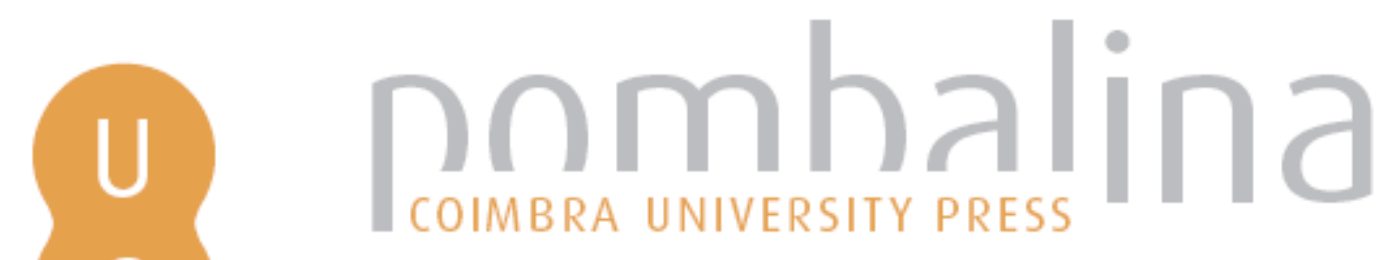

\title{
A formalidade e o risco: uma relação tênue entre formas de ocupação em Salvador - Bahia, Brasil
}

\author{
Autor(es): $\quad$ Falcão, Plínio Martins \\ Publicado por: Imprensa da Universidade de Coimbra; RISCOS - Associação \\ URL \\ persistente: URI:http://hdl.handle.net/10316.2/34941 \\ DOI: $\quad$ DOI:http://dx.doi.org/10.14195/978-989-96253-3-4_141 \\ Accessed : $\quad$ 26-Apr-2023 13:38:11
}

A navegação consulta e descarregamento dos títulos inseridos nas Bibliotecas Digitais UC Digitalis, UC Pombalina e UC Impactum, pressupõem a aceitação plena e sem reservas dos Termos e Condições de Uso destas Bibliotecas Digitais, disponíveis em https://digitalis.uc.pt/pt-pt/termos.

Conforme exposto nos referidos Termos e Condições de Uso, o descarregamento de títulos de acesso restrito requer uma licença válida de autorização devendo o utilizador aceder ao(s) documento(s) a partir de um endereço de IP da instituição detentora da supramencionada licença.

Ao utilizador é apenas permitido o descarregamento para uso pessoal, pelo que o emprego do(s) título(s) descarregado(s) para outro fim, designadamente comercial, carece de autorização do respetivo autor ou editor da obra.

Na medida em que todas as obras da UC Digitalis se encontram protegidas pelo Código do Direito de Autor e Direitos Conexos e demais legislação aplicável, toda a cópia, parcial ou total, deste documento, nos casos em que é legalmente admitida, deverá conter ou fazer-se acompanhar por este aviso.

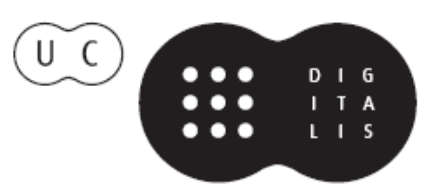



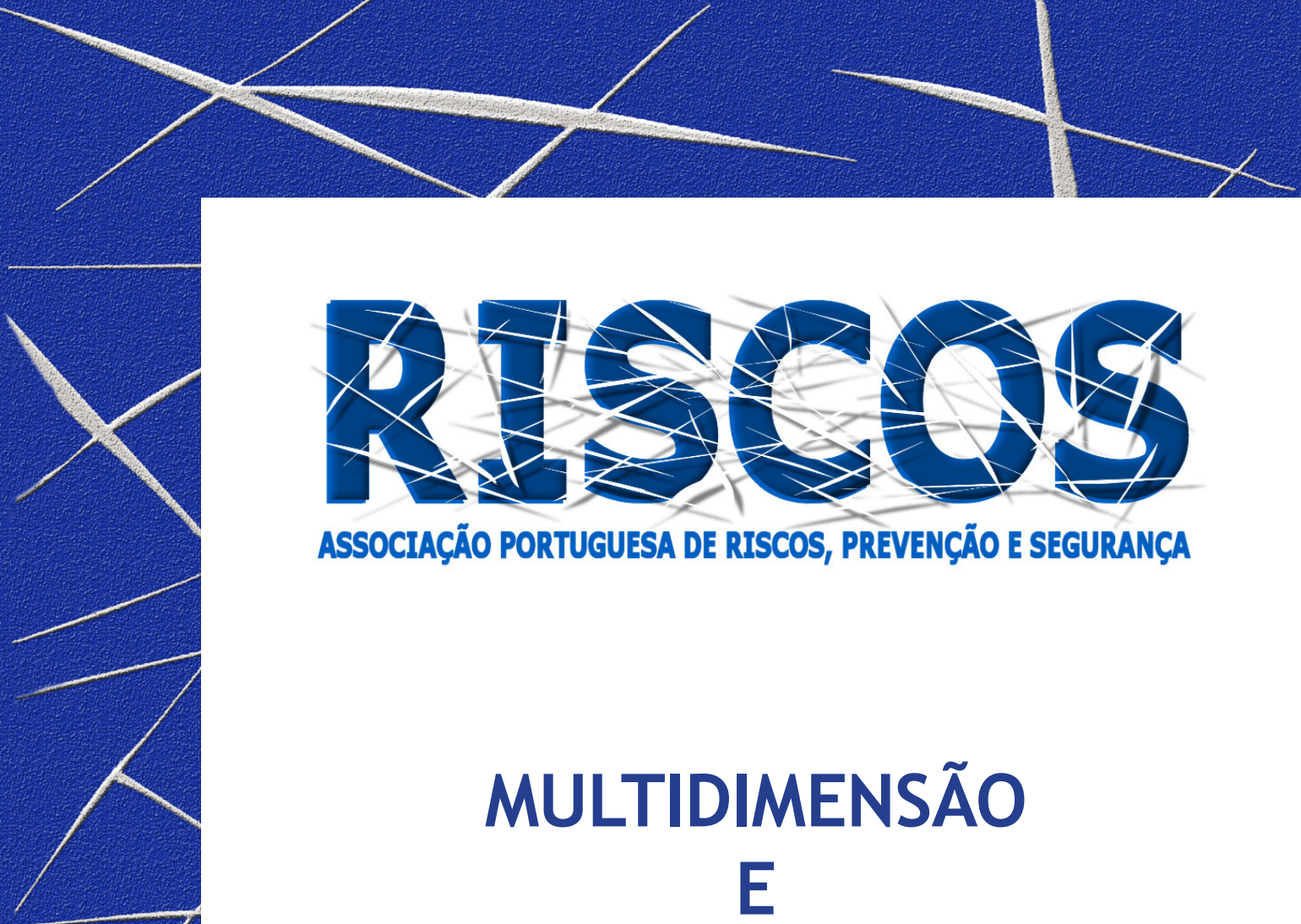

ASSOCIAÇÃO PORTUGUESA DE RISCOS, PREVENCCÃO E SEGURANÇA

MULTIDIMENSÃO

E
TERRITÓRIOS DE RISCO

III Congresso Internacional

I Simpósio Ibero-Americano

VIII Encontro Nacional de Riscos

Guimarães

2014 


\title{
A FORMALIDADE E O RISCO: UMA RELAÇÃO TÊNUE ENTRE FORMAS DE OCUPAÇÃO EM SALVADOR - BAHIA, BRASIL
}

\author{
Plínio Martins Falcão \\ Departamento de Geografia, Instituto Federal da Bahia - IFBA \\ Grupo de Pesquisa Terra\&Mar - CNPq / IFBA - Campus Salvador \\ pliniomf@gmail.com
}

\begin{abstract}
RESUMO
Salvador, com quase 3 milhões de habitantes, persiste no problema de pessoas que vivem em áreas suscetíveis, a exemplo de encostas, morros ou áreas instáveis. Todavia, um fato observado leva a crer que nesta cidade onde tantos processos espaciais e sociais se interralacionam, é possível notar uma paridade entre o dito formal e informal pelo planejamento, num local excêntrico no que tange formas de ocupação e topografia. Este trabalho teve como objetivo apresentar um panorama do risco na lógica da construção formal em Salvador, identificando áreas e construções suscetíveis, que inexplicavelmente passaram por alguma instância do planejamento urbano, permitindo o uso de áreas suscetíveis ou sem adequação para ocupar de modo mais seguro. A metodologia utilizada consistiu em levantamento bibliográfico, uso de cartografias, imagens e trabalhos de campo, o que permitiu, dentre os resultados, uma sistematização e coletânea por meio do recorte imagético de áreas de instabilidade de encostas.
\end{abstract}

Palavras-chave: Ocupação formal; Risco; Encostas; Salvador.

Introdução

Com mais de 200 milhões de habitantes (IBGE, 2014) o Brasil se caracteriza como um país urbano, cuja população está em torno de $80 \%$ concentrada nas cidades. Estas correspondem aos espaços de maior dinamismo na realidade nacional, visto que a aglomeração de pessoas e a evolução dos diversos setores socioeconômicos impulsionam uma infinidade de atividades que tornam estes espaços polarizantes no que tange a atenção e concentração de cidadãos. São nesses espaços urbanos mais ocupados e / ou adensados, por sua vez, que se encontram os principais problemas da ordem socioambiental.

Este trabalho teve como objetivo apresentar um panorama do risco na lógica da construção formal em Salvador, capital da Bahia, identificando áreas e construções suscetíveis, que, inexplicavelmente, passaram por alguma instância do planejamento urbano, permitindo o uso de áreas suscetíveis ou sem adequação para ocupar de modo mais seguro. A metodologia utilizada consistiu em três etapas: (a) pesquisa bibliográfica; (b) análise de documentação cartográfica; (c) trabalhos de campo, que permitiram a construção de um conjunto de imagens que definem o tema tratado.

\section{Salvador: ocupação e áreas de risco}

Fundada em 29 de março de 1549 para ser a primeira capital do Brasil, por uma ação e decreto imperial do Estado português com a igreja católica, estabeleceu-se numa área de visão privilegiada do sítio, com o intuito de assegurar o controle contra ataques oriundos da área marítima. Sua localização inicial alude ao seu próprio processo de urbanização ao longo dos últimos quatro séculos: no topo da escarpa da falha de Salvador, que atualmente corresponde ao limite físico entre as chamadas Cidade Alta e Baixa. 


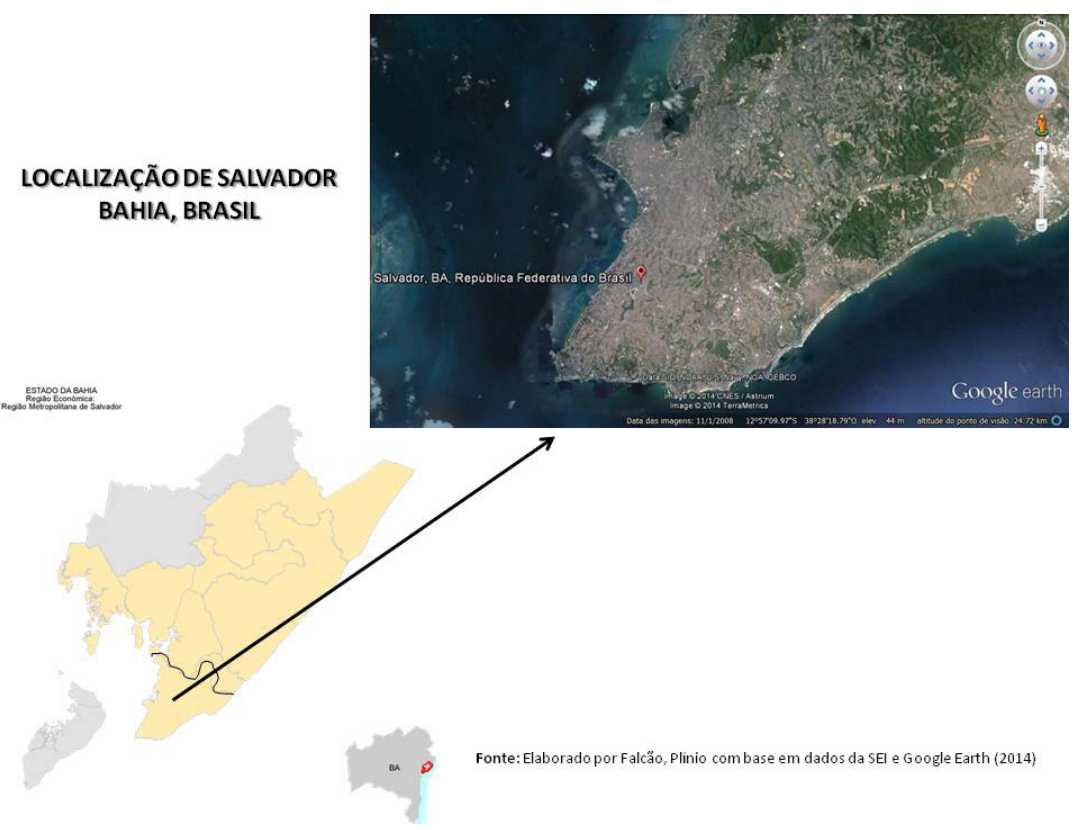

Mapa 1 - Localização de Salvador...

A história urbana mostra que Salvador, desde cedo, apresentou uma ocupação densa das áreas bordejantes à Baía de Todos os Santos, permanecendo as áreas de vale sem aproveitamento ou apenas voltadas às práticas de subsistência local. No entanto, progressivamente a expansão foi se interiorizando com dois períodos de destaque na espacialização: a metade do século XIX (readequação da Barra, Rio Vermelho, Amaralina, vias centrais antigas como Baixa dos Sapateiros, Dique, Itapagipe, Pirajá e Largo do Tanque) e do século XX (abertura das avenidas de vale como Centenário, Nazaré, Mário Leal Ferreira / Bonocô).

Processos formais de ocupação em áreas suscetíveis

Ainda que a enganharia, bem como o planejamento de cidades, nas últimas décadas tenham avançado consideravelmente sobre a qualidade das técnicas voltadas à construção, é possível dizer que algumas áreas são ocupadas, no caso do tecido urbano de Salvador, por meio uma especulação imobiliária espacial que não tece observações quando se trata de considerar a suscetibilidade a deslizamentos em algumas áreas íngremes. É certo que numa cidade cuja população norteia os 3 milhões de habitantes (IBGE, 2014), as demandas por uso e ocupação do espaço se acentuam na medida que os terrenos nas áreas centrais e planas foram ficando mais caros.

No entanto, o que se tem visto nos últimos anos é uma expressa invasão (no sentido de ocupar) a áreas que, teoricamente, seriam inviáveis para a construção, sobretudo, de estruturas com elevadas e pesadas. Valer-se pelas altas tecnologias da engenharia civil tornou-se aposta para o mercado imobiliário soteropolitano, haja vista a necessidade de construção de tantos novos edifícios a suprir uma demanda de classe média crescente, sobretudo na última década. Nessa corrida entraram os empreendimentos que vão de médio a elevado padrão, importando basicamente as relações de comercialização e serviços diretamente associados. 
Todavia, as questões ambientais, que perpassam a dinâmica da natureza e a participação do homem enquanto sujeito social, destoam das práticas alusivas apenas à dinâmica de manutenção de um dos mercados mais pujantes na economia das grandes cidades brasileiras, que é a construção civil. Em paralelo, e no caso específico da capital soteropolitana, sucumbe à crítica o planejamento da cidade, que em todas as versões dos seus planos diretores, desde a década de 1970, manteve-se alóctone ao processo de ocupação de encostas, seja de modo irregular ou - como na atualidade - formalizado. Daí então que parte dos problemas são visualizados na ótica das ocupações de encostas por famílias de baixa renda, cuja associatividade entre a geologia local, tipologia de solos (pedologia) da capital, declividades, os índices pluviométricos em torno de $2000 \mathrm{~mm}$ anuais e as construções realizadas sem o uso adequados de técnicas, podem resultar mais facilmente em desastres, partindo do princípio de que se tratando de áreas íngremes, todos estão suscetíveis. Ainda assim, os ditames da formalização pregada pela engenharia e pelos planos diretores, mesmo quando cumpridas, não eximem diversos cidadãos da sua condição de vulnerabilidade ou mesmo de risco. (Figura 1)

Dessa forma, o que se verifica em Salvador, na atualidade, é que embora muitas áreas cujo relevo íngreme denotam situação de risco em ocupação, diversas edificações de padrão residencial foram construídas nessas áreas, com o aval do poder público pautado na legislação vigente, cujas restrições recaem apenas sobre algumas áreas, como os terrenos em topo das escarpas de falha, que historicamente já são densamente ocupadas pelas classes menos abastadas. Em diversas partes da cidade é possível verificar como construções ditas formais se mesclam a uma situação de suscetibilidade que não se diferencia tanto dos panoramas normalmente observados e criticados, ainda que as técnicas de engenharia tenham sido aplicadas. (Figura 2)

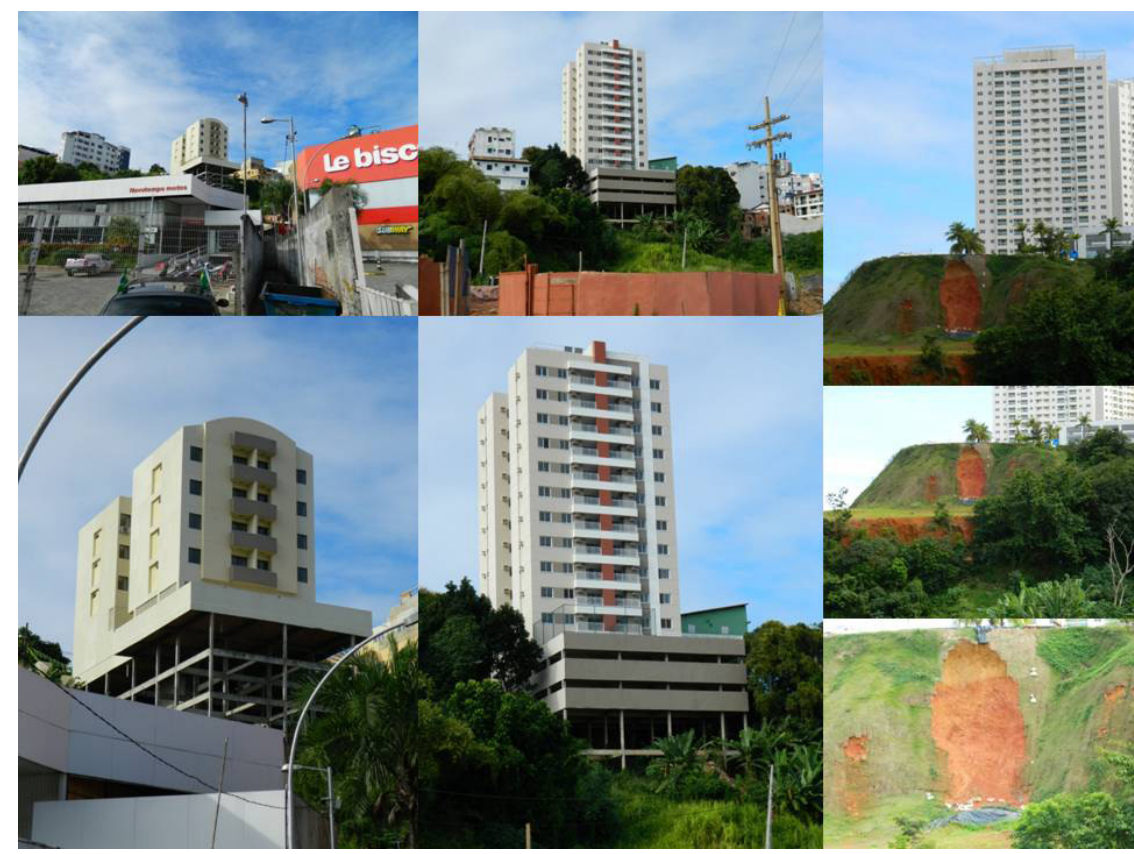

Fig. 1 - Construções formais em Salvador - Bahia

Fonte: Falcão, Plínio (2014) 


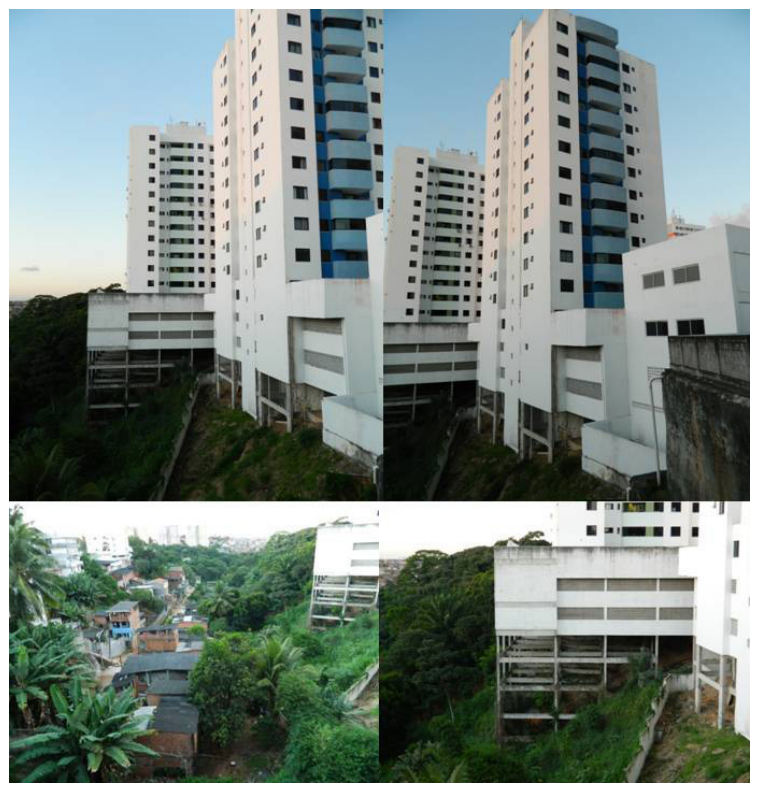

Fig. 2 - Construções formais em Salvador - Bahia Fonte: Falcão, Plínio (2014)

Muito embora exista um estado da arte com relação às situações de vulnerabilidade e riscos em áreas íngremes da capital baiana, os estudos ainda não se voltaram para essa complexidade de que mesmo os estratos mais equilibrados do ponto de vista da renda, ocupam espaços que, variavelmente, poderiam ser evitados. Brandão e Olmos (1981) apresentaram um esquema com as áreas instáveis quanto a movimentação do solo na cidade de Salvador, agrupando estas em três categorias: (i) Área da escarpa de falha (Falha de Salvador), (ii) As avenidas de vale e (iii) Áreas ocupadas por camadas de baixa renda.

Entretanto, são em vários pontos dessas áreas, na atualidade, onde estão cravadas diversas estruturas, edificações e/ou empreendimentos que, salvo as técnicas de engenharia, se justapõem às mesmas condições naturais que tornam a vulnerabilidade crônica, a exemplo do tipo de solo, as infiltrações e moldes de escoamento superficial provenientes dos níveis de precipitação. Tais fatos comprovam a necessidade de ajustamento das questões pertinentes ao planejamento da cidade, com vistas a uma atenção mais minuciosa aos modos de uso de áreas ainda desocupadas, mas que poderão, num futuro próximo, vir a atender às demandas do capital imobiliário, criando novas vulnerabilidades na capital.

\section{Conclusão}

O século XXI é marcado por diversas transformações no planeta, tendo a questão ambiental se tornado mais evidente no que tange às mudanças naturais e antropogênicas. 0 foco do presente texto é chamar atenção para algumas questões que norteiam o pensamento urbano e ambiental, com foco nas questões de risco e vulnerabilidade em áreas íngremes da cidade de Salvador, já que a capital integra a lista de uma das cidades mais excêntricas no que tange às formas de ocupação, devido seu contexto social e peculiar topografia. 
Sendo assim, verificou-se que mesmo os próprios processos formais de uso do espaço se submetem, por diversas questões, a áreas que, tolerantemente, não deveriam ser ocupadas e aedificadas.

\section{Bibliografia}

BRANDÃO, M.A.; OLMOS, S.A. (1981) Encostas. Por que e onde caem. Salvador: Oceplan - PMS / GESEC.

IBGE - Instituto Brasileiro de Geografia e Estatística. (2014) Censo demográfico - Estimativas populacionais. Disponível em: http//:www.ibge.gov.br Acesso em: 20 de julho de 2014.

\section{Agradecimentos}

Ao INSTITUTO FEDERAL DA BAHIA - IFBA, instituição na qual o autor atua como docente e pesquisador do seu quadro permanente. 